Reprod. Nutr. Dévelop., 1988, 28 (1), 133-134.

\title{
Influence d'une bactérie méthanogène sur l'activité cellulolytique et le métabolisme de deux espèces de champignons cellulolytiques du rumen in vitro. Résultats préliminaires
}

\author{
G. FONTY ( $\left.{ }^{1}\right)\left({ }^{2}\right)$, Ph. GOUET ('), Véronique SANTE (') \\ (1) Laboratoire de Microbiologie \\ I.N.R.A., Theix, 63122 Ceyrat, France. \\ (2) Laboratoire de Biologie comparée des Protistes, CNRS UA 138 \\ Université de Clermont II, 63170 Aubière.
}

Summary. The extend of cellulose degraded by $P$. communis and $S$. communis, two rumen fungi, was greater in the presence of a methanogenic bacteria than in monoculture. Cocultures produced more acetic acid and less ethanol and lactate than did monocultures.

Les transferts interspécifiques d'hydrogène dans le rumen sont reconnus comme le facteur principal régulant les profils fermentaires (Wolin 1974). L'utilisation de I'hydrogène par les bactéries méthanogènes hydrogénophiles permet une déviation du métabolisme des microorganismes hydrolytiques ou fermentatifs vers la production d'acétate. Deux exemples de ces interactions ont été étudiés jusqu'ici, I'un avec Ruminococcus flavefaciens (bactérie cellulolytique) (Latham et Wolin, 1977), I'autre avec Neocallimastix frontalis (champignon cellulolytique) (Bauchop et Mountfort, 1981), associés à Methanobrevibacter ruminantium (bactérie méthanogène). Notre objectif a été ici d'étudier l'action de $M$. ruminantium sur l'activité cellulolytique et le métabolisme des deux autres espèces de champignons du rumen; Piromonas communis et Sphaeromonas communis.

Matériel et méthodes. La quantité de cellulose de papier filtre broyé (Whatman $n^{\circ}$ 1) dégradée par $P$. communis (souche 1) et par $S$. communis (souche 121) en monoculture ou en coculture avec $M$. ruminantium a été déterminée après $2,4,6$ et 8 jours d'incubation à $39^{\circ} \mathrm{C}$. Les cultures ont été réalisées en tube de Hungate sous atmosphère de $\mathrm{CO}_{2}$ sur le milieu de Latham et Wolin (1977). Dans chaque tube, $100 \mathrm{mg}$ de cellulose ont été ajoutés à $10 \mathrm{ml}$ de milieu de culture. Pour chaque temps d'incubation, 3 tubes ont été ensemencés. La quantité de cellulose non dégradée a été déterminée après centrifugation de la culture à $500 \mathrm{~g}$ pendant $30 \mathrm{~min}$. Le culot a été ensuite séché à l'étuve à $80^{\circ} \mathrm{C}$ pendant $72 \mathrm{~h}$. La cellulose disparue a été estimée par rapport à celle de tubes témoins non inoculés. Les produits de la fermentation (acides gras volatils, acide lactique, éthanol, gaz) 
ont été analysés en chromatographie en phase gazeuse après 8 jours de culture (Jouany 1982).

Résultats. En monoculture, $P$. communis a présenté une activité cellulolytique importante, puisque après $2,4,6$ et 8 jours de culture il avait dégradé respectivement $10,20,28$ et $50 \%$ de la cellulose initiale. Par contre, $S$. communis a eu une activité beaucoup plus faible $112 \%$ de cellulose dégradée après 8 jours de culture). L'activité de ces deux espèces a été beaucoup plus élevée en coculture avec $M$. ruminantium. Après 8 jours d'incubation celle de $P$. communis a été multipliée par 1,5 et celle de $S$. communis par 2,5.

En coculture, le métabolisme des champignons a été dévié vers une plus grande production d'acétate au détriment des composés réduits (éthanol, lactate) (voir tabl. 1). Cependant le bilan complet des fermentations devra être précisé en mesurant notamment la production de formiate, la production quantitative des gaz, les sucres présents dans le milieu mais non fermentés, ainsi que la biomasse microbienne produite. Cette étude confirme le rôle primordial joué par les espèces hydrogénophiles dans la cellulolyse. Les mécanismes des interactions entre ces 2 champignons et la bactérie méthanogène, qui peuvent s'apparenter à celui mis en évidence chez $R$. flavefaciens, restent toutefois à rechercher.

TABL. 1. - Produits terminaux de la fermentation de la cellulose par $\mathrm{P}$. communis et $\mathrm{S}$. communis, en monoculture et en coculture avec M. ruminantium après 8 jours d'incubation.

\begin{tabular}{|c|c|c|c|c|}
\hline \multirow[b]{2}{*}{$\begin{array}{c}\text { Produits } \\
\text { terminaux } \\
(\mathrm{mM} . \mathrm{L}-1)\end{array}$} & \multicolumn{4}{|c|}{ Culture } \\
\hline & P. communis & $\begin{array}{c}\text { P. communis } \\
+ \\
\text { M. ruminantium }\end{array}$ & S. communis & $\begin{array}{c}\text { S. communis } \\
+ \\
\text { M. ruminantium }\end{array}$ \\
\hline Acétate & 15,7 & 39,8 & 14,3 & 48,7 \\
\hline Lactate & 8,9 & 1,1 & 5,4 & 0,7 \\
\hline Ethanol & 7,5 & 0,7 & 3,4 & 0,7 \\
\hline Hydrogène & +++ & + & $++t$ & + \\
\hline Méthane & 0 & +++ & 0 & $++t$ \\
\hline
\end{tabular}

Bauchop T., Mountfort D. O., 1981. Appl. environ. Microbiol., 42, 1103-1110.

Jouany J. P., 1982. Sci. Aliments, 2, 131-140.

Latham M. J., Wolin M. J., 1977. Appl. environ. Microbiol., 34, 297-301.

Wolin M. J., 1974. Am. J. Clin. Nutr., 27, 1320-1328. 